\title{
Human T-Cell Leukemia Virus Type 1 Infection Is a Risk Factor for Atherosclerosis
}

\author{
Hiroaki Takeoka $^{\text {a, b, e }}$, Yasuko Sagara ${ }^{\mathrm{c}}$, Seizaburo Ksashiwagi ${ }^{\mathrm{d}}$, Shigeki Nabeshima ${ }^{\mathrm{a}}$
}

\begin{abstract}
Background: Infection, such as by human immunodeficiency virus (HIV), has been reported to cause atherosclerosis by inducing inflammation. Because human T-cell leukemia virus type 1 (HTLV-1) is a retrovirus, as is HIV, we investigated the possible influence of HTLV1 on the pathogenesis of atherosclerosis by use of established atherosclerosis parameters.
\end{abstract}

Methods: The study was done on Iki Island, Fukuoka, an area endemic for HTLV-1. The data of 1,424 residents who reported to an annual health check were available for analysis. Anti-HTLV-1 antibody status and factors associated with atherosclerosis were examined, including maximum intima-media thickness (Max-IMT) and brachialankle pulse wave velocity (PWV).

Results: HTLV-1 positive participants had significantly higher MaxIMT $(1.15 \pm 0.55$ vs. $1.08 \pm 0.61 \mathrm{~mm}, \mathrm{P}=0.04)$ and PWV $(1,760.6$ \pm 414.5 vs. $1,657.1 \pm 425.5 \mathrm{~cm} / \mathrm{s}, \mathrm{P}<0.01)$ values than did those negative. Moreover, in multiple regression analysis (odds ratio: 1.39, $\mathrm{P}<0.01$ ) of participants with Max-IMT $1.1 \mathrm{~mm}$ or over, HTLV-1 was extracted as an independent factor for the development of atherosclerosis.

Conclusion: Our results indicate that HTLV-1 infection confers a high risk of atherosclerosis, although its opposite relation is also possible. It is important to carefully follow the health status of HTLV-1 carriers.

Keywords: HTLV-1; Atherosclerosis; IMT

Manuscript submitted February 24, 2021, accepted March 5, 2021

Published online March 19, 2021

${ }^{a}$ General Medicine, Fukuoka University Hospital, 7-45-1 Nanakuma, Jonanku, Fukuoka 814-0180, Japan

${ }^{\mathrm{b}}$ General Medicine, Kyushu University Hospital, 3-1-1 Maidashi, Higashi-ku, Fukuoka 812-8582, Japan

'Department of Quality, Japanese Red Cross Kyushu Block Blood Center, 1-21 Kamikoga, Chikushino, Fukuoka 818-8588, Japan

${ }^{\mathrm{d}}$ Fukuoka Center, Japanese Red Cross Kyushu Block Blood Center, 1-2-1 Kamikoga, Chikushino, Fukuoka 818-8588, Japan

${ }^{e}$ Corresponding Author: Hiroaki Takeoka, General Medicine, Fukuoka University Hospital, 7-45-1 Nanakuma, Jonan-ku, Fukuoka 814-0180, Japan. Email: htakeoka@fukuoka-u.ac.jp

doi: https://doi.org/10.14740/jocmr4457

\section{Introduction}

Chronic inflammation and immune activation are major risk factors for atherosclerosis [1]. Infection with viral or bacterial agents is recognized as a possible risk factor for atherosclerosis, alongside other risk factors such as hypertension, smoking, hypercholesterolemia, hyperglycemia and genetic factors $[2,3]$. Examples of viral pathogens found in atherosclerotic plaque are: hepatitis $\mathrm{C}$ virus (HCV), cytomegalovirus (CMV), herpes simplex viruses (HSV), human immunodeficiency virus (HIV) and Epstein-Barr virus (EBV) [3, 4]. HIV-infected patients are at increased risk for cardiovascular disease (CVD) events, even those on antiretroviral therapy (ART) and whose HIV infection is well controlled [5, 6]. Clinical observations and imaging studies have shown an increasing prevalence of subclinical atherosclerosis in HIVinfected patients $[7,8]$.

Recent studies have shown that HIV infection is a predictor of increased intima-media thickness (IMT) [9, 10]. IMT is measured by high-resolution B-mode ultrasound and is used for the assessment of atherosclerosis. Increased IMT is an important predictor of future cerebrovascular and cardiovascular events [11]. A recent study reported an association between atherosclerosis and human T-cell leukemia virus type 1 (HTLV-1) in a population of elderly people in whom IMT was measured $[12,13]$.

HTLV-1, first diagnosed in 1980 in a patient with cutaneous lymphoma, can cause inflammatory diseases [14]. A characteristic of this virus is that over $90 \%$ of carriers remain asymptomatic. In symptomatic patients, it can cause serious disorders such as adult T-cell leukemia/lymphoma (ATLL), HTLV-1-associated myelopathy/tropical seizures (HAM/ TSP), HTLV-1 infection-related dermatitis (IDH), Sjogren's syndrome, thyroiditis, lymphocytic pneumonia, uveitis, Behcet's disease, polymyositis and arthropathy [15]. This virus is regionally specific and is endemic to southwestern Japan, Central and South America, the Caribbean Islands, Central Australia and sub-Saharan Africa [16].

Inflammation is of paramount importance in the development of atherosclerosis [17, 18], and HTLV-1 is a chronic inflammatory disease that contributes inflammatory stimulation that could initiate or exacerbate atherosclerosis. The causative factors of atherosclerosis have been reported to include an inflammatory mechanism involving the release of cytokines and chemokines. Increased levels of cytokines and local inflammatory chemokines induce leukocyte activation. As a result, 
mononuclear cells infiltrate the atherosclerotic plaque [19].

To clarify the association between atherosclerosis and HTLV-1, we investigated the IMT and brachial-ankle pulse wave velocity (PWV) of residents who took a routine health examination for all ages.

\section{Materials and Methods}

\section{Design}

The area of this retrospective, cross-sectional study is Iki, an island in southwestern Japan, with a population of about 32,000 . Life is similar to that of people living in other parts of Japan, fishing and agriculture are the main sources of income and HTLV-1 is endemic [20]. A free medical examination consisting of a physical examination, questionnaire, blood cell count and blood chemistry analysis including HTLV-1 antibodies was conducted. This study was approved by the Institutional Review Board of Kyushu University Hospital and was conducted in accordance with the human experimentation guidelines of the US. The study included 1,424 residents (482 male and 942 female, age range 19 - 90 years, average age 63.2 years). All participants underwent a health checkup sponsored by the local public health center in June of 2005. Participants must be 18 years of age or older to consent to participate in the health checkup, excluding those under 18 years of age and those who cannot consent to participate in the health checkup.

Height and weight were measured and body mass index $(B M I)$ was calculated $\left(B M I=\right.$ weight $/$ height $\left.^{2}\left(\mathrm{~kg} / \mathrm{m}^{2}\right)\right)$. Systolic and diastolic blood pressures (SBP and DBP) were measured at rest in a sitting position. Blood samples were collected from all of the subjects after overnight fasting, and sera were stored at $-20{ }^{\circ} \mathrm{C}$ until testing for routine serum biochemistry and anti-HTLV-1 antibody tests. Serum levels of total cholesterol (TC), triglyceride (TG), high-density lipoprotein cholesterol (HDL-C), low-density lipoprotein cholesterol (LDL-C), fasting blood glucose (FBG), HbAlc and C-reactive protein (CRP) were determined by a commercial blood chemistry analysis machine in a professional laboratory. The smoking status was categorized as "none", "past" or "present".

\section{Detection of anti-HTLV-1 antibody}

Screening for anti-HTLV-1 antibody was done by the passive particle agglutination (PA) method (Fujirebio, Tokyo, Japan) for all samples. Positive results were confirmed by Western blot analysis according to the manufacturer's protocol (Fujirebio, Tokyo, Japan), with bands gp46, p53, p24 and p19 indicating positivity. Samples for which the results of both methods were positive were considered positive for anti-HTLV-1 antibody and those determined to be seroreactive for anti-HTLV-1 by PA alone were considered to be negative for HTLV-1. In this study, subjects positive for anti-HTLV-1 antibody were defined as HTLV-1 carriers.

\section{Monitoring of atherosclerosis parameters}

We examined IMT, plaque and stenosis of the extra-cranial carotid arteries with B-mode ultrasound using a 7.5 MHz linear array transducer and a high-resolution instrument (Fukuda Denshi, Japan). Carotid artery echoes were measured by trained physicians using standardized procedures. IMT is defined as the distance between two echo lines separated by a hypoechoic or anechoic space. The outer line corresponds to the medial-adventitial border and the inner line represents the luminal-intimal border. The IMT is measured at the end of the diastole phase at locations 20, 25 and $30 \mathrm{~mm}$ proximal to the flow divider in the distal wall of the right and left common carotid arteries. The maximum IMT value was defined as Max-IMT. The Max-IMT of the common carotid artery was measured in the right and left carotid arteries, and the larger value was used. The upper limit of normal for IMT was set at $1.0 \mathrm{~mm}[21,22]$, and 1.1 $\mathrm{mm}$ or more was considered atherosclerotic plaque. According to the criteria of the carotid ultrasound examination guidelines, we classified Max-IMT 1.1 mm or over as atherosclerosis [23].

PWV was measured using a VP-1000 (BP-203RPEII; Colin Corp., Ltd, Osaka, Japan). Pneumatic cuffs were placed on each arm and ankle, electrocardiographic electrodes were placed on each wrist and a microphone for heart sound detection was placed on the left end of the sternum to record the volume waveform of the brachial and ankle arteries. PWV was automatically calculated from the transit time of the pulse wave by the length of the arterial segment between the brachial artery and ankle (which was automatically calculated from the body height). Framingham score was used as an independent variable for risk stratification, and PWV 1,400 (cm/s) or over was defined as atherosclerotic CVD [24].

\section{Statistical analysis}

Values are described as mean \pm standard deviation (SD). Items for analysis included age, sex, BMI, blood pressure, FBG, HbA1c, smoking history, TC, LDL-C, TG, HDL-C, CRP, Max-IMT and PWV. The unpaired $t$-test and Mann-Whitney $\mathrm{U}$ analysis were used for analysis of differences in means between the HTLV-1 carriers and antibody-negative control participants. Multivariable-adjusted analysis was used to determine correlations between Max-IMT $1.1 \mathrm{~mm}$ or over and other associated variables. For all tests, a "P" value less than 0.05 was considered to have statistical significance.

All statistical analyses were performed using EZR [25], a modified version of $\mathrm{R}$ commander.

\section{Results}

\section{Clinical characteristics}

Table 1 shows the age- and sex-based prevalence of antiHTLV-1 antibody among the residents of Iki Island. Of the 1,424 residents who participated in this study, $272(19.1 \%)$ 
Table 1. Age- and Sex-Specific Prevalence of Anti-HTLV-1

\begin{tabular}{|c|c|c|c|c|c|c|}
\hline \multirow[b]{2}{*}{ Age (years) } & \multicolumn{2}{|r|}{ Male } & \multicolumn{2}{|r|}{ Female } & \multicolumn{2}{|r|}{ Total } \\
\hline & No. tested & $\begin{array}{l}\text { Anti-HTLV-1 } \\
\text { positive, No. (\%) }\end{array}$ & No. tested & $\begin{array}{l}\text { Anti-HTLV-1 } \\
\text { positive, No. (\%) }\end{array}$ & No. tested & $\begin{array}{l}\text { Anti-HTLV-1 } \\
\text { positive, No. (\%) }\end{array}$ \\
\hline $10-19$ & 0 & 0 & 1 & 0 & 1 & 0 \\
\hline $20-29$ & 2 & 0 & 8 & $1(12.5)$ & 10 & $1(10.0)$ \\
\hline $30-39$ & 31 & $1(3.2)$ & 57 & $4(7.5)$ & 88 & $5(5.7)$ \\
\hline $60-69$ & 143 & $20(14.0)$ & 301 & $77(25.6)$ & 444 & $97(21.8)$ \\
\hline $70-79$ & 161 & $34(21.1)$ & 249 & $75(30.1)$ & 410 & 109 (26.6) \\
\hline 80 or over & 34 & $4(11.8)$ & 29 & $9(31.0)$ & 63 & $13(20.6)$ \\
\hline Total & 482 & $69(14.3)$ & 942 & $203(21.5)$ & 1424 & $272(19.1)$ \\
\hline
\end{tabular}

HTLV-1: human T-cell leukemia virus type 1.

were HTLV-1 positive, with the prevalence significantly higher for residents 60 years and older than for those under 60 years $(\mathrm{P}<0.01)$. All $272 \mathrm{HTLV}-1$ positive are asymptomatic carriers. The remaining 1,152 were HTLV-1 negative. The clinical characteristics of the HTLV-1 positive and HTLV-1 negative groups are shown in Table 2. Age, HbA1c and smoking were significantly different between the two groups.

\section{Comparison of the atherosclerosis parameters}

The Max-IMT and PWV levels of the HTLV-1 positive and negative groups are shown in Table 2. The Max-IMT (1.15 \pm
0.55 vs. $1.08 \pm 0.61 \mathrm{~mm}, \mathrm{P}=0.04)$ and $\mathrm{PWV}(1,760.6 \pm 414.5$ vs. $1,657.1 \pm 425.5 \mathrm{~cm} / \mathrm{s}, \mathrm{P}<0.01)$ of the HTLV-1 positive group was significantly higher than that of the HTLV-1 negative group.

\section{Risk factors for atherosclerosis by multiple regression analysis}

Table 3 shows that the multivariable-adjusted odds ratio (OR) (95\% confidence interval $(\mathrm{CI}))$ per $1.1 \mathrm{~mm}$ over increase in Max-IMT was $1.39(1.02-1.89)(\mathrm{P}<0.01)$. We adjusted for age, sex, smoking, SBP, BMI, PWV and HbA1c. Importantly,

Table 2. Clinical Characteristics

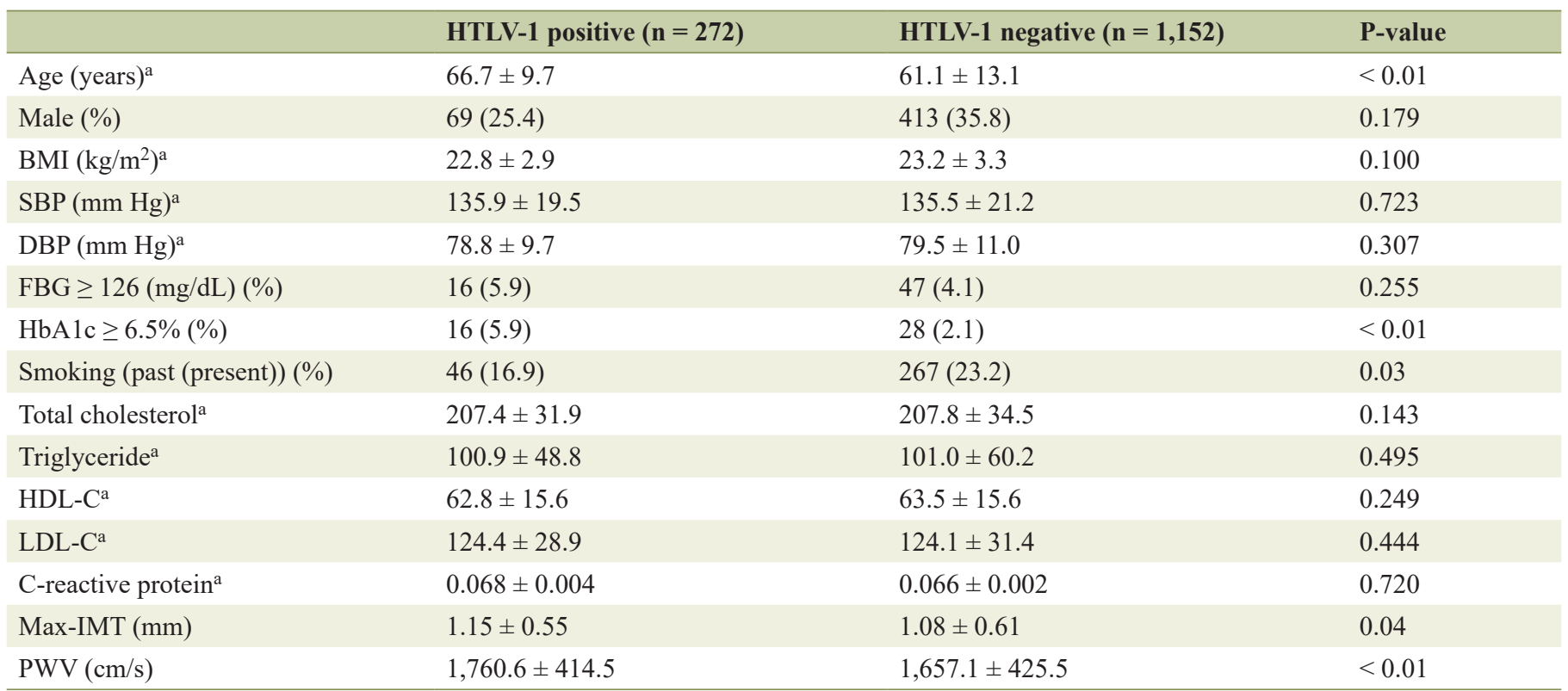

aAverage \pm standard deviation (range). HTLV: human T-cell leukemia virus type 1; BMI: body mass index; SBP: systolic blood pressure; DBP: diastolic blood pressure; FBG: fasting blood glucose; HDL-C: high-density lipoprotein cholesterol; LDL-C: low-density lipoprotein cholesterol; Max-IMT: maximum intima-media thickness; PWV: brachial-ankle pulse wave velocity. 
Table 3. Impact of HTLV-1 on Carotid Plaque

\begin{tabular}{|c|c|c|c|c|c|c|c|}
\hline & $\begin{array}{l}\text { Max-IMT } 1.1 \\
\text { mm or over }\end{array}$ & Crude OR & $95 \%$ CI & P-value & $\begin{array}{l}\text { Multivariable- } \\
\text { adjusted OR }\end{array}$ & $95 \%$ CI & P-value \\
\hline HTLV-1 positive (\%) & $103(37.9)$ & 1.66 & $1.25-2.18$ & $<0.01$ & 1.39 & $1.02-1.89$ & $<0.01$ \\
\hline HTLV-1 negative (\%) & $310(26.9)$ & Reference & & & Reference & & \\
\hline
\end{tabular}

HTLV-1: human T-cell leukemia virus type 1; Max-IMT: maximum intima-media thickness; OR: odds ratio; Cl: confidence interval.

in addition to these common, well-known atherosclerotic risk factors, HTLV-1 infection was revealed as an independent risk factor for the progression of atherosclerosis.

\section{Discussion}

We found a significant, positive correlation in Max-IMT for the HTLV-1 positive group. Moreover, HTLV-1 positivity was extracted as an independent factor for the development of atherosclerosis.

An association between HTLV-1 and atherosclerosis has been reported [12, 13], and high-resolution B-mode ultrasound imaging, especially measurement of carotid IMT, has been validated as an indicator of vascular risk [26]. There is no radiation exposure to the patient and it is relatively inexpensive. PWV, a non-invasive clinical indicator of aortic stiffness [27], can also be used to predict cardiovascular events and identify hypertensive patients in the general population [28, 29]. HTLV-1 infection has been positively associated with atherosclerosis $[30,31]$.

We found that our HTLV-1 positive group had significantly higher Max-IMT and PWV values than the HTLV-1 negative group. Furthermore, as a result of adjusting for age, sex, smoking, BMI, SBP and PWV, HTLV-1 was found to be a significant independent factor of arteriosclerosis. Change in systemic inflammation has been seen in HTLV-1-infected patients, even in those who are asymptomatic [18]. Because HTLV-1 potentially causes atherosclerosis, this suggests that the progression of atherosclerosis is influenced not only by age but also by HTLV-1 persistence.

As with HIV $[32,33]$, both atherosclerosis and chronic HTLV-1 infection are disease states characterized by the presence of low-grade chronic inflammation. Atherosclerosis has also been associated with metabolic risk factors [16]. Recent studies have shown that viral and bacterial causes may be responsible for coronary artery disease and its restenosis after angioplasty. Infections have been linked to inflammatory cytokines, and these have been linked to factors that accelerate CVD. Other proposed associations include CMV, chlamydia pneumoniae, Helicobacter pylori, EBV, HIV and other infectious diseases [34].

Plasma levels of monocyte chemotactic protein-1 (MCP1) are associated with risk factors for atherosclerosis [34, 35], and further experimental studies may help to further understand our results.

There are several limitations to this study. In carotid echo, the measurement results may be slightly affected by differences in evaluators. Although there was a broad age range, our participants tended to be of higher age (median age 63 years). Intervention for younger participants needs to be done to promote early detection of arteriosclerosis and disease prevention.

\section{Conclusion}

Our results indicate that HTLV-1 infection is causative of atherosclerosis and CVD. Routine cardiovascular monitoring of HTLV-1-infected patients, even asymptomatic carriers, is important. In this study, the HTLV-1 positive group showed significantly higher Max-IMT and PWV values than the HTLV-1 negative group. In addition, HTLV-1 positive was extracted as an independent factor for the development of atherosclerosis. These results suggest that HTLV-1 infection confers a high risk of atherosclerosis, although the reverse relation is possible, especially for the younger generations with HTLV-1. Careful attention should be paid to the early stages of the progression of atherosclerosis.

\section{Acknowledgments}

We thank Hisatomi Arima for providing advice on statistical analysis.

\section{Financial Disclosure}

None to declare.

\section{Conflict of Interest}

None to declare.

\section{Informed Consent}

Written informed consent was obtained from all residents and patients included in this survey.

\section{Author Contributions}

Dr. Takeoka was the lead researcher and analyzed the data. Dr. Sagara assisted by doing laboratory testing for the HTLV-1 and supervised and helped design the study. Dr. Kashiwagi and Dr. Nabeshima supervised and helped design the study. 


\section{Data Availability}

The authors declare that data supporting the findings of this study are available within the article.

\section{References}

1. Pignoli P, Tremoli E, Poli A, Oreste P, Paoletti R. Intimal plus medial thickness of the arterial wall: a direct measurement with ultrasound imaging. Circulation. 1986;74(6):1399-1406.

2. Rosenfeld ME. Inflammation and atherosclerosis: direct versus indirect mechanisms. Curr Opin Pharmacol. 2013;13(2):154-160.

3. Campbell LA, Rosenfeld ME. Infection and atherosclerosis development. Arch Med Res. 2015;46(5):339-350.

4. Ibrahim AI, Obeid MT, Jouma MJ, Moasis GA, Al-Richane WL, Kindermann I, Boehm M, et al. Detection of herpes simplex virus, cytomegalovirus and Epstein-Barr virus DNA in atherosclerotic plaques and in unaffected bypass grafts. J Clin Virol. 2005;32(1):29-32.

5. Freiberg MS, Chang CC, Kuller LH, Skanderson M, Lowy E, Kraemer KL, Butt AA, et al. HIV infection and the risk of acute myocardial infarction. JAMA Intern Med. 2013;173(8):614-622.

6. Triant VA, Lee H, Hadigan C, Grinspoon SK. Increased acute myocardial infarction rates and cardiovascular risk factors among patients with human immunodeficiency virus disease. J Clin Endocrinol Metab. 2007;92(7):25062512.

7. Summers DN, Richmond S, Wechsler BM. Cigarette smoke: effects on lactate extraction in the presence of severe coronary atherosclerosis. Am Heart J. 1971;82(4):458-467.

8. Hsue PY, Hunt PW, Schnell A, Kalapus SC, Hoh R, Ganz $\mathrm{P}$, Martin JN, et al. Role of viral replication, antiretroviral therapy, and immunodeficiency in HIV-associated atherosclerosis. AIDS. 2009;23(9):1059-1067.

9. Hsue PY, Lo JC, Franklin A, Bolger AF, Martin JN, Deeks SG, Waters DD. Progression of atherosclerosis as assessed by carotid intima-media thickness in patients with HIV infection. Circulation. 2004;109(13):1603-1608.

10. Mangili A, Gerrior J, Tang AM, O'Leary DH, Polak JK, Schaefer EJ, Gorbach SL, et al. Risk of cardiovascular disease in a cohort of HIV-infected adults: a study using carotid intima-media thickness and coronary artery calcium score. Clin Infect Dis. 2006;43(11):1482-1489.

11. O'Leary DH, Polak JF, Kronmal RA, Manolio TA, Burke GL, Wolfson SK, Jr. Carotid-artery intima and media thickness as a risk factor for myocardial infarction and stroke in older adults. Cardiovascular Health Study Collaborative Research Group. N Engl J Med. 1999;340(1):14-22.

12. Layegh P, Shoeibi A, Nikkhah K, Ghabeli Juibary A, Raftari S, Darbarpanah S, Boroumand R, et al. Can HTLV-1 infection be a potential risk factor for atherosclerosis? Intervirology. 2014;57(6):365-368.
13. Yamanashi H, Koyamatsu J, Nagayoshi M, Shimizu Y, Kawashiri SY, Kondo H, Fukui S, et al. Human T-cell leukemia Virus-1 infection is associated with atherosclerosis as measured by carotid intima-media thickness in Japanese community-dwelling older people. Clin Infect Dis. 2018;67(2):291-294.

14. Poiesz BJ, Ruscetti FW, Gazdar AF, Bunn PA, Minna JD, Gallo RC. Detection and isolation of type $C$ retrovirus particles from fresh and cultured lymphocytes of a patient with cutaneous T-cell lymphoma. Proc Natl Acad Sci U S A. 1980;77(12):7415-7419.

15. Proietti FA, Carneiro-Proietti AB, Catalan-Soares BC, Murphy EL. Global epidemiology of HTLV-I infection and associated diseases. Oncogene. 2005;24(39):60586068.

16. Gessain A, Cassar O. Epidemiological Aspects and World Distribution of HTLV-1 Infection. Front Microbiol. 2012;3:388.

17. Ross R. Atherosclerosis - an inflammatory disease. N Engl J Med. 1999;340(2):115-126.

18. Shin WS, Szuba A, Rockson SG. The role of chemokines in human cardiovascular pathology: enhanced biological insights. Atherosclerosis. 2002;160(1):91-102.

19. Waehre T, Damas JK, Gullestad L, Holm AM, Pedersen TR, Arnesen KE, Torsvik H, et al. Hydroxymethylglutaryl coenzyme a reductase inhibitors down-regulate chemokines and chemokine receptors in patients with coronary artery disease. J Am Coll Cardiol. 2003;41(9):14601467.

20. Kishihara Y, Furusyo N, Kashiwagi K, Mitsutake A, Kashiwagi S, Hayashi J. Human T lymphotropic virus type 1 infection influences hepatitis $\mathrm{C}$ virus clearance. J Infect Dis. 2001;184(9):1114-1119.

21. Honda O, Sugiyama S, Kugiyama K, Fukushima H, Nakamura S, Koide S, Kojima S, et al. Echolucent carotid plaques predict future coronary events in patients with coronary artery disease. J Am Coll Cardiol. 2004;43(7):1177-1184.

22. Handa N, Matsumoto M, Maeda H, Hougaku H, Ogawa S, Fukunaga R, Yoneda S, et al. Ultrasonic evaluation of early carotid atherosclerosis. Stroke. 1990;21(11):15671572.

23. Bots ML, Dijk JM, Oren A, Grobbee DE. Carotid intima-media thickness, arterial stiffness and risk of cardiovascular disease: current evidence. J Hypertens. 2002;20(12):2317-2325.

24. Yamashina A, Tomiyama H, Arai T, Hirose K, Koji Y, Hirayama Y, Yamamoto Y, et al. Brachial-ankle pulse wave velocity as a marker of atherosclerotic vascular damage and cardiovascular risk. Hypertens Res. 2003;26(8):615622.

25. Kanda Y. Investigation of the freely available easy-touse software 'EZR' for medical statistics. Bone Marrow Transplant. 2013;48(3):452-458.

26. Kobayashi K, Akishita M, Yu W, Hashimoto M, Ohni M, Toba K. Interrelationship between non-invasive measurements of atherosclerosis: flow-mediated dilation of brachial artery, carotid intima-media thickness and pulse wave velocity. Atherosclerosis. 2004;173(1):13-18. 
27. van Popele NM, Grobbee DE, Bots ML, Asmar R, Topouchian J, Reneman RS, Hoeks AP, et al. Association between arterial stiffness and atherosclerosis: the Rotterdam Study. Stroke. 2001;32(2):454-460.

28. Blacher J, Asmar R, Djane S, London GM, Safar ME. Aortic pulse wave velocity as a marker of cardiovascular risk in hypertensive patients. Hypertension. 1999;33(5):11111117.

29. Shokawa T, Imazu M, Yamamoto H, Toyofuku M, Tasaki N, Okimoto T, Yamane K, et al. Pulse wave velocity predicts cardiovascular mortality: findings from the HawaiiLos Angeles-Hiroshima study. Circ J. 2005;69(3):259-264.

30. Abolbashari S, Ghayour-Mobarhan M, Ebrahimi M, Meshkat Z. The role of human T-lymphotropic virus (HTLV) in cardiovascular diseases: A review of literature. ARYA Atheroscler. 2018;14(4):183-187.
31. Deeks SG. HIV infection, inflammation, immunosenescence, and aging. Annu Rev Med. 2011;62:141-155.

32. Hansson GK. Inflammatory mechanisms in atherosclerosis. J Thromb Haemost. 2009;7(Suppl 1):328-331.

33. Ismail A, Khosravi H, Olson $\mathrm{H}$. The role of infection in atherosclerosis and coronary artery disease: a new therapeutic target. Heart Dis. 1999;1(4):233-240.

34. Deo R, Khera A, McGuire DK, Murphy SA, Meo Neto Jde P, Morrow DA, de Lemos JA. Association among plasma levels of monocyte chemoattractant protein-1, traditional cardiovascular risk factors, and subclinical atherosclerosis. J Am Coll Cardiol. 2004;44(9):1812-1818.

35. Inadera H, Egashira K, Takemoto M, Ouchi Y, Matsushima K. Increase in circulating levels of monocyte chemoattractant protein-1 with aging. J Interferon Cytokine Res. 1999;19(10):1179-1182. 